\title{
On the Choice of Welfare Standards in Competition Law
}

\section{Citation}

Louis Kaplow, On the Choice of Welfare Standards in Competition Law (Harvard John M. Olin Discussion Paper Series, No. 693, May 2011).

\section{Permanent link}

http://nrs.harvard.edu/urn-3:HUL.InstRepos:30064218

\section{Terms of Use}

This article was downloaded from Harvard University's DASH repository, and is made available under the terms and conditions applicable to Other Posted Material, as set forth at http:// nrs.harvard.edu/urn-3:HUL.InstRepos:dash.current.terms-of-use\#LAA

\section{Share Your Story}

The Harvard community has made this article openly available.

Please share how this access benefits you. Submit a story.

\section{Accessibility}




\title{
HARVARD
}

JOHN M. OLIN CENTER FOR LAW, ECONOMICS, AND BUSINESS

\author{
ON THE CHOICE OF \\ WELFARE STANDARDS IN \\ COMPETITION LAW
}

\author{
Louis Kaplow
}

Discussion Paper No. 693

$05 / 2011$

\author{
Harvard Law School \\ Cambridge, MA 02138
}

This paper can be downloaded without charge from:

The Harvard John M. Olin Discussion Paper Series:

http://www.law.harvard.edu/programs/olin_center/

The Social Science Research Network Electronic Paper Collection:

http://ssrn.com/ 
JEL Classes D40, D63, H23, K21, L40

\title{
On the Choice of Welfare Standards in Competition Law
}

\author{
Louis Kaplow*
}

\begin{abstract}
This article addresses two issues relating to the choice between a consumer welfare and total welfare standard for competition law. First, it considers whether distributive considerations may favor a consumer welfare standard, or at least some underweighting of producer surplus in a total welfare assessment. The argument that focusing on consumer welfare is poorly targeted to general redistributive objectives is correct but not decisive since the distributive incidences of consumer and producer surplus differ significantly. By contrast, the argument that it is more efficient to rely exclusively on the tax and transfer system to achieve general distributive objectives is normatively powerful. Second, the relevance of the preexisting level of price elevation (relative to a competitive, marginal cost benchmark) is found to be quite different under the two standards. For a given additional price increase caused by anticompetitive activity, the marginal sacrifice of consumer welfare is greatest when there is no preexisting elevation and gradually falls as the initial elevation grows. By contrast, the marginal sacrifice of total welfare (deadweight loss) is negligible when there is no preexisting elevation and rises as the initial elevation grows. This difference has implications for competition policy, most directly for that toward horizontal mergers and price-fixing, along with practices that facilitate coordinated price elevation.
\end{abstract}

Forthcoming, Goals of Competition Law (Zimmer, ed., Edward Elgar).

Couis Kaplow. All rights reserved.

\footnotetext{
*Harvard Law School and National Bureau of Economic Research. This essay derives from a lecture that was the keynote address for the Fifth Annual Conference of the Academic Society for Competition Law, on "Goals of Competition Law," and the inauguration for the Center for Advanced Studies in Law and Economics at the University of Bonn. The first part of this essay grows out of suggestions in Louis Kaplow and Carl Shapiro, Antitrust, in Handbook of Law and Economics, vol. 2, edited by A. Mitchell Polinsky and Steven Shavell 1073, 1166-69 (2007), and in other prior work, cited below, outside the competition law context. The second part develops an idea first identified in my recent work on price fixing: Louis Kaplow, Toward a Test for Price Fixing, Antitrust Law Journal (forthcoming 2011). I am grateful to conference participants for their comments and also to the John M. Olin Center for Law, Economics, and Business at Harvard Law School for additional financial support.
} 


\title{
On the Choice of Welfare Standards in Competition Law
}

\author{
Louis Kaplow
}

(C) 2011. All Rights Reserved.

\section{Introduction}

The interpretation and application of competition law to horizontal restraints, mergers, and exclusionary (abusive) practices by dominant firms depends on what the laws' goals are deemed to be. Increasingly, and especially in the United States, a concern for economic welfare is taken to be central. As a result, much attention has been devoted to determining which rules best advance welfare. There nevertheless remains dispute over whether total welfare should be the objective, as is conventional under a welfare economic approach, or only consumer welfare should count. ${ }^{1}$

This essay examines two sets of issues that bear on this choice. First, supposing that society is concerned with the equality of the distribution of income, does it make sense to employ competition law in pursuit of this aim, in particular by giving primary or exclusive weight to consumer welfare, downgrading or ignoring producer welfare? Second, what are the differential implications of the choice between consumer and total welfare for the importance of the existing degree of price elevation?

To begin, some definitions are useful. Here, consumer welfare will be taken to refer to the consumer surplus obtained by final consumers, where consumer surplus refers to the difference between consumers' valuations (the most they would be willing to pay) and the price they actually pay. ${ }^{2}$ Producer surplus is the difference between the price producers are paid for

${ }^{1}$ See, e.g., Louis Kaplow and Carl Shapiro, Antitrust, in Handbook of Law and Economics, vol. 2, edited by A. Mitchell Polinsky and Steven Shavell 1073, 1166-69 (2007) (discussing the issue and citing contrasting sources in the merger context).

${ }^{2}$ Unfortunately, the term consumer welfare, which naturally denotes the welfare of consumers, is often used to refer to total welfare, specifically including producers' surplus, largely as a consequence of Robert Bork's usage in The Antitrust Paradox: A Policy at War with Itself (1978). See Barak Y. Orbach, The Antitrust Consumer Welfare Paradox, Journal of Competition Law \& Economics (forthcoming 2011). Others use the term consumer welfare to denote a general endorsement of some welfare standard without committing either to consumer or total welfare. See, e.g., Antitrust Modernization Commission, Report and Recommendations 3 \& n.22 (April 2007) (stating that "Antitrust law prohibits anticompetitive conduct that harms consumer welfare." and clarifying in footnote that "Debate continues about the precise definition of 'consumer welfare.' . . The Supreme Court has not ruled specifically on this issue. The Commission's use of the term "consumer welfare" does not imply a choice of a particular definition.." (emphasis added)). A possible explanation is that, for external audiences, the term consumer welfare seems both more comprehensible and more appealing than total welfare, even though total welfare may be thought to be a more sensible objective. The latter attitude is reflected by the Commission's endorsement of giving greater weight to efficiencies in horizontal mergers. See id. at 10 (recommendation 6 is that "The Federal Trade Commission and the Antitrust Division of the Department of Justice should give substantial weight to evidence demonstrating that a merger will enhance efficiency." and recommendation 7 is that "The Federal Trade Commission and the Antitrust Division of the Department of Justice should increase the weight they give to certain types of efficiencies. For example, the agencies and courts should give greater credit for certain fixed-cost efficiencies, such as research and development expenses, in dynamic, innovation-driven industries where marginal costs are low relative to typical prices."). 
what they sell and the cost of production. Total welfare is the sum of consumer surplus (or welfare) and producer surplus. Relatedly, the term deadweight loss refers to the sacrifice in total surplus due to price being elevated above marginal cost (which welfare loss is the excess of consumers' valuations over marginal cost for units not purchased due to price elevation). From this perspective, lost consumer surplus is the sum of deadweight loss and the amount transferred from consumers to producers (the latter being equal to the product of the quantity sold and the magnitude of the price elevation). The latter is not part of deadweight loss (the reduction in total welfare) precisely because it is a transfer, to producers.

It is helpful at the outset also to identify some of the issues not considered here. The subject of competition law's proper objectives is large. ${ }^{3}$ In particular, there has long been a broad debate about whether the law's purpose should be viewed as primarily or solely concerned with economic welfare (in some sense) or also (instead) as addressed to other sorts of purposes, some political or social. This essay does not partake directly in this controversy and instead simply assumes that some weight is to be given to economic welfare. ${ }^{4}$ Even regarding the narrower question of the choice between consumer and total welfare, this essay is not comprehensive. It does not consider the extent to which fidelity to controlling legal provisions (statutes, treaties, precedents) may dictate an answer. Nor does it address other considerations bearing on the normative choice, including whether one or another standard may be easier to apply or whether one might be a practical proxy for the other, subjects that have received significant attention of late, particularly regarding the review of horizontal mergers. ${ }^{5}$

Section 2 addresses the question of whether distributive objectives may sensibly be advanced by adopting a consumer welfare standard (or, more moderately, giving less weight to producer surplus than to consumer surplus). It suggests a negative answer on the ground that distributive objectives are better achieved through the tax and transfer system, with competition law advancing total welfare and hence giving equal weight to consumer and producer surplus. A traditional argument for relying on taxes and transfers that applies in many contexts is that they are better targeted than indirect means, such as the use of competition law. This point is certainly true since there is great heterogeneity among consumers and among producers, and the extent and even direction of redistribution is not always the same. (A merger between firms producing luxury goods is commonly mentioned.) Nevertheless, because producers

\footnotetext{
${ }^{3}$ Indeed, the conference volume in which this essay appears is devoted entirely to the subject.

${ }^{4}$ In other work, I have advanced in great detail the position that legal policy generally (thus including competition policy) should be concerned exclusively with welfare, which is to say, the well-being of individuals. See Louis Kaplow and Steven Shavell, Fairness versus Welfare (2002). Among the arguments is that giving weight to nonwelfarist considerations entails endorsement of the view that it is sometimes best to make everyone in society worse off. Many proposed competition law objectives on one hand do not appear to be denominated in welfare terms and are often presented as alternatives or supplements to considerations of welfare, yet on the other hand may, on reflection, possibly be understood as proxies for aspects of welfare or suggestions that more subtle welfare consequences (such as through reinforcing a democratic political regime) not be excluded from conventional welfare-based analysis of competition policy. For further discussions of such possibilities (without specific reference to competition law), see $i d$., especially chapter $8 \mathrm{~A}$.

${ }^{5}$ For an excellent discussion of some of the arguments recently advanced, see Joseph Farrell and Michael L. Katz, The Economics of Welfare Standards in Antitrust, Competition Policy International 2(2): 3, 15-27 (Autumn 2006).
} 
(specifically, their owners and other beneficiaries of increased profits) are, on average, wealthier than consumers, this argument is not in itself decisive.

A second, more convincing argument is that the use of indirect means such as competition law to redistribute income - specifically, adoption of less efficient rules (ones that fail to maximize total welfare) because of their more favorable distributive consequences - is an inefficient means of redistribution. Accomplishing the same degree of redistribution through the tax and transfer system allows the redistribution to be achieved at lower cost, which means that both producers and consumers can be made better off. Thus, if the purpose is to help consumers as a whole, using a means that helps them less hardly makes sense.

Section 3 examines how the degree of preexisting price elevation bears on the implications of using a consumer welfare versus a total welfare standard. The fundamental point is that the marginal and total cost under these two standards changes differently as prices are elevated above a competitive level. For a one unit increase in price, the loss in consumer surplus is (approximately) one times the current quantity. At the competitive price, this quantity is high compared to when the price is significantly elevated, so the marginal loss in consumer surplus is high. As the price rises, the marginal loss in consumer surplus falls. The total sacrifice in consumer surplus sacrifice, to be sure, is higher, but the total loss in consumer surplus rises at a decreasing rate.

By contrast, the marginal sacrifice in total welfare is negligible starting at a competitive price. The reason is that deadweight loss is determined by the quantity reduction times the degree to which consumers' valuation for that quantity exceeds the competitive price (equal to marginal cost). When price is only slightly elevated, this latter component is very small, so the increment to deadweight loss is correspondingly small. However, starting at a significantly elevated price (and supposing that the decline in quantity due to a similar slight further increase in price is the same), consumers' average valuations for that quantity greatly exceed marginal cost, so the increment to deadweight loss is much greater. In sum, the loss in total welfare also rises with price, but the loss starts out very small and increases at an increasing rate - it accelerates.

This fundamental difference between the relevance of price elevation to consumer welfare and to total welfare means that, in various competition law settings, different priorities might arise. For example, with horizontal mergers, suppose we are considering a proposed combination that is predicted to cause a given elevation in price. If the pre-merger market is fairly competitive, this increment will cause a relatively large loss in consumer welfare but a very small loss in total welfare. Hence, the merger is significantly more problematic under a consumer welfare standard. However, if the pre-merger market is much less competitive, the increment will cause a smaller loss in consumer welfare than in the prior case but a relatively large loss in total welfare. Current merger policy in most regimes is stricter in the latter situation, which would make sense if the objective was total welfare, not consumer welfare. Yet most regimes purport to be designed to advance consumer rather than total welfare, so there is a 
discrepancy between existing rules and claimed objectives. ${ }^{6}$ Section 3 also considers implications for price-fixing enforcement, and the analysis has relevance as well to rules addressed to practices employed by dominant firms.

\section{Distributive Objectives}

\subsection{Overview}

The notion that government functions should be allocated to different agencies that specialize in different tasks is a familiar one. Perhaps the most well-known statement on the present subject is Richard Musgrave's description in his 1959 treatise that, among other things, distinguishes the allocative function and the distributive function. ${ }^{7}$ The former (involving the provision of public goods and control of externalities, for example) should be concerned with allocative efficiency. The latter, with control over such instruments as the income tax and transfer programs, should concentrate on how best to achieve distributive objectives.

The virtues of specialization as applied to government agencies are likewise well known. An environmental protection commission should concern itself with the environment, not the quality of schools. The defense department should advance security and not be diverted by concerns about the safety of pharmaceuticals. And so forth.

Of course, complete specialization is not always optimal. Moreover, and perhaps more important as an explanatory matter in the present setting, the desires of many academics and officials in various agencies are not so readily constrained. It is tempting to address problems that one views as socially important whenever possible, regardless of one's supposed jurisdiction or specialization. One sees oneself as being more compassionate and more important if one attends to distributive considerations, regardless of the role one happens to occupy. Furthermore, the costs of achieving distribution indirectly are not widely appreciated. Because of the latter factor, this section carefully considers the two primary limitations or costs of indirect redistribution, poor targeting and reduced efficiency. Then it addresses some practical political considerations that might be thought to bear on the problem.

\subsection{Targeting}

The most familiar, and most debated, limit of competition law in achieving distributive objectives is that it (like most indirect means of redistribution) tends to be poorly targeted in comparison to the tax and transfer system. The latter is designed to be targeted as well as is feasible for distributive purposes. Payments under income taxes and receipts under transfer programs are related to income and other pertinent factors. The latter include age, disability, and family configuration. By contrast, the categories of consumers and of producers are not nearly

\footnotetext{
${ }^{6}$ One possibility is that such statements about consumer welfare do not actually reflect rejection of a total welfare standard, as explained in note 2 .

${ }^{7}$ Richard A. Musgrave, The Theory of Public Finance, ch. 1 (1959).
} 
as well aligned with distributive objectives.

Consumers - the focus of a consumer welfare standard - are obviously heterogeneous, as they comprise all members of society. Viewing consumption as a whole, clearly the rich benefit relatively more than the poor from maintaining competitive pricing because they consume more. On average, the benefits would tend to be proportional to consumption, which rises less-thanproportionally with income - but not to a huge extent (except at the very top of the income distribution), particularly when the matter is viewed on a lifetime basis. As a result, raising consumer welfare across the board certainly generates far greater gains to those who are economically better off.

Some products are purchased widely, with intensities that vary by income level. Flour, sugar, and other staples comprise a much higher proportion of the poor's consumption, luxury goods more for the rich. Many competition law cases involve intermediate goods producers, where the incidence is far more complicated. For example, computer chips are used in computers that in turn are used by consumers (fairly widely) and by other producers. The other producers in turn supply all manner of goods both directly to consumers and to other producers (who, in turn ...). Hence, the incidence of a price increase on computer chips is quite complicated to determine. Note further that some of the higher prices paid by producers further down the supply chain may not be passed on to consumers but instead reduce producer surplus.

Nor are producers monolithic. First, not all rents from higher prices necessarily translate to profits. For example, labor, especially when unionized, might appropriate part of the gain, as might management. The portion of profits going to owners (itself partially taxed, which in turn may then be redistributed) benefits varying groups. Significant equity interests are owned in retirement accounts and directly by middle-income individual investors. Some firms are owned by insiders, who may be wealthy individuals or family groups or, in the case of very small firms, individuals who are closer to the average.

One approach would be to adjust the weight given to consumer and producer surplus on a case-by-case basis. Thus, if a particular merger is under review, one could ascertain who are the actual consumers of the firms' products (including intermediate producers, in which case one would further trace through the effects of the price increases, at each stage determining the likely pass-on rates and so forth). For producer surplus, one would assess which constituencies within the firm would gain and then determine the distribution of economic well-being of the beneficiaries. (For stock held by other firms or in the name of institutions who hold on behalf of individuals, further tracing would be required.) Even a superficial description of the task indicates that it would be daunting, quite difficult to do well and highly costly. As a consequence, few favor this approach, and some see it as a decisive objection to the use of competition law to achieve redistribution. ${ }^{8}$

${ }^{8}$ See, e.g., Farrell and Katz, supra note 5, at 10 (mentioning uncertainty about distributive effects as a reason against crediting distributive concerns); Ken Heyer, Welfare Standards and Merger Analysis: Why Not the Best?, Competition Policy International 2(2) 29, 49 (Autumn 2006). 
A more general targeting strategy, however, seems plausible: one that does not trace the economic incidence case by case but instead broadly gives more weight to consumer surplus. It is generally recognized that, despite all of the complications noted at the outset of this subsection, it remains true that the distribution of producer surplus is significantly more favorable to the very wealthy and not very favorable at all to the lower half of the income distribution relative to the distribution of consumer surplus. ${ }^{9}$ Accordingly, it seems possible to increase the degree of redistribution, if that is what one wishes to do, by giving greater weight to consumer welfare.

It is not, however, generally appreciated that the foregoing analysis does not support the view that exclusive weight should be accorded to consumer welfare. Consider, for example, prohibiting a merger that reduces consumer surplus by 1 but raises producer surplus by 10 (say, on account of a savings in fixed costs that would not plausibly be passed on to consumers).

Even if the vast majority of the gain in producer surplus goes to the rich, it may well be true that low- and middle-income individuals would tend to benefit enough from the relatively large gain in producer surplus to offset the modest loss in consumer surplus. In this regard, one should also keep in mind that, for the average of all consumption, a substantial majority is by individuals with above-median income (and that for intermediate goods, some "consumer surplus" may really be producer surplus).

In principle, one could attempt to compute the average distributive incidence of consumer and producer surplus (perhaps with different figures for different settings, e.g., intermediate versus final goods) and, based on the results, determine how one might weight consumer and producer surplus to maximize the degree of redistribution accomplished in this indirect manner. As suggested, the weight on producer surplus would be lower than that on consumer surplus, but it still might be significantly greater than zero (normalizing the weight on consumer surplus to be one). Of course, this method is much less precisely targeted than is the tax and transfer system, yet it does on the surface accomplish some further redistribution. As mentioned in the introduction, whether such analysis is appropriate as a matter of legal and institutional constraints is not a question considered in this essay (although the discussion of politics in subsection 2.4 bears somewhat on this matter).

\subsection{Efficiency}

The claim advanced in this subsection is that redistribution is more efficiently accomplished through the tax and transfer system. If this is so, one can achieve a given degree of redistribution at less cost if one accomplishes it all through the tax and transfer system rather than doing some of it through competition law. Or, for a given cost of redistribution, one can accomplish more redistribution if it is confined to the tax and transfer system, with competition law being designed to maximize total welfare. Stated yet a third way - and the one that will be employed in the argument below - one can make all income groups better off by removing any redistribution through competition law (achieved by deviating from the maximization of total

\footnotetext{
${ }^{9}$ See, e.g., Russell Pittman, Consumer Surplus as the Appropriate Standard for Antitrust Enforcement, Competition Policy International 3(2): 205, 208-10 (Autumn 2007) (citing evidence).
} 
welfare) and substituting a similar degree of redistribution through the tax and transfer system.

The analytical argument supporting this conclusion in the context of legal rules is first advanced in an article by Steven Shavell and is subsequently developed in a number of ways in my own writing (including a key article with Shavell). ${ }^{10}$ Even so, this argument has not fully disseminated, and it has received very little attention in competition law scholarship addressed to the choice between consumer and total welfare standards. ${ }^{11}$

To begin, one must ask why redistribution cannot be costlessly accomplished to an ideal extent through the tax and transfer system (for, if it could, it would be obvious that achieving additional redistribution indirectly and inefficiently, such as through competition law, would be unwise). The core limitation concerns the incentive cost of redistribution. Because we tax more heavily those who earn more income and subsidize individuals through transfer programs to the extent they earn less income, the tax and transfer system creates incentives to reduce labor effort, which is inefficient. This efficiency cost limits the extent of redistribution that is feasible and desirable and makes any redistribution that is undertaken socially costly.

It is therefore natural to ask whether indirect redistribution, such as through competition law, can help in light of this limitation on direct redistribution through the tax and transfer system. The answer, in basic settings that are most relevant for present purposes, is that, unfortunately, it cannot. The fundamental reason is that indirect redistribution, to the extent that it is successful, distorts labor supply to the same degree as would accomplishing that amount of

\footnotetext{
${ }^{10}$ See, e.g., Steven Shavell, A Note on Efficiency vs. Distributional Equity in Legal Rulemaking: Should Distributional Equity Matter Given Optimal Income Taxation?, American Economic Review (AEA Papers and Proceedings) 71, no. 2: 414 (1981); Louis Kaplow and Steven Shavell, Why the Legal System Is Less Efficient than the Income Tax in Redistributing Income, Journal of Legal Studies 23: 667 (1994); Louis Kaplow, On the (Ir)relevance of Distribution and Labor Supply Distortion to Government Policy, Journal of Economic Perspectives 18, no. 4: 159 (2004); Louis Kaplow, The Theory of Taxation and Public Economics (2008).

${ }^{11}$ For example, Steven C. Salop, Question: What is the Real and Proper Antitrust Welfare Standard? Answer: The True Consumer Welfare Standard, submitted to the Antitrust Modernization Commission (Nov. 4, 2005) (unpublished) at 14-17, addresses the redistributive question but adopts a somewhat dismissive attitude since redistribution through taxes and is costly (which, at the text explains, is correct but ultimately beside the point) and fails to address the literature bearing on the subject. (He cites Kaplow and Shavell (2002), supra note 4, which is largely not on point and he gives the wrong title, one suggesting a lack of appreciation of the topic of the miscited book. By contrast, he does advocate that competition law violations be viewed as intentional torts (at pp. 23-26), a sort of argument aggressively attacked in that book - in general and, for torts in the whole of chapter 3 - but Salop does not mention the book, other pertinent literature, or any of the arguments in that part of his essay.) Pittman, supra note 9, despite making a number of good points, displays a cavalier attitude toward this argument and the pertinent literature. He (at p. 208) refers to Kaplow (2004), supra note 10, as a paper that refuses to consider the issue (rather than offering a decisive objection to taking Pittman's position on the question), and (at p. 210) refers to Richard Musgrave's famous treatise as a "paper" by an individual named "William" Musgrave. He revisits the subject (at pp. 212-213), arguing that we should not wait until a redistributive government comes along, making one wonder whether he would endorse agencies redistributing in the opposite direction (ignoring consumer welfare and considering only producer surplus) if he lived in a more redistributive regime or if there was a change in government (as there was in the United States two years after his article was published). For further discussion of the political dimension, see subsection 2.4. Even those, such as Farrell and Katz, supra note 5, at 11, and Heyer, supra note 8, at 50 , who are favorable to confining redistributive efforts to the tax and transfer system do not make reference to the key efficiency argument or the pertinent literature.
} 
redistribution through the tax and transfer system. Accordingly, one is left with the inefficiencies of sacrificing total welfare in the realm of competition law with no offset to the redistributive inefficiencies that are present in the tax and transfer system.

To elaborate on the idea, consider what happens when less (or no) weight is given to producer surplus, resulting in competition law outcomes that push down producer surplus and push up consumer surplus (but by a lesser amount, since we are contemplating deviations from the maximization of total welfare). The former is tantamount to a tax on producer surplus, which is a sort of profits tax (or, in many jurisdictions for many of the relevant firms, like a corporate income tax). To have the desired redistributive effect, we are supposing that this tax comes disproportionately from the rich. That is, we are in essence raising the taxes on the rich, by reducing, say, the investment returns that they can achieve. Likewise, the rise in consumer surplus (which is tantamount to a small, across-the-board reduction in an otherwise uniform value-added tax) is assumed to redistribute (relative to the fall in producer surplus) toward the poor. If indeed these are the effects - and we are assuming this to be so if any redistribution is to be accomplished through competition law's giving added weight to consumer welfare relative to producer surplus - then it follows that, just to this extent, the result is tantamount to raising taxes on the rich to increase transfers to the poor. And, if that is the consequence, then we have the same distorting effect on labor supply.

Put another way, following the parenthetical statements just above, one way to have redistributed more income through the tax and transfer system would have been to slightly raise corporate or profits taxes, using the revenue to reduce the rate of a value-added tax or other broad tax on consumption. In terms of redistribution and labor supply distortion, the consequences would, in essence, by the same in this case as when such is done through competition law (by underweighting or ignoring producer surplus).

Given that indirect redistribution through competition law entails the same labor supply distortion as direct redistribution through the income tax and transfer system, it is necessarily inferior. The reason is that, to accomplish additional redistribution, it was necessary to deviate from the maximization of total welfare. That is, when we give less (or no) weight to producer surplus relative to consumer surplus, we are led to adopt policies (whenever our consumer welfare tilt makes a difference) under which the increase in consumer surplus is less than the fall in producer surplus, in order (indirectly) to enhance redistribution. (Keep in mind that if the rise in consumer surplus exceeds the fall in producer surplus, then the effect is to raise total welfare, so the outcome is that which would be adopted under a total welfare standard in any event.) Thus, society suffers from the inefficiency cost from redistribution per se and also the further inefficiency cost due to inefficient competition law outcomes.

To illustrate, compare two competition law rules in the following setting. One rule (which aims to maximize total welfare) produces an outcome with consumer surplus of 10 and producer surplus of 10 , for total welfare of 20. The other rule (which aims to maximize consumer welfare) produces an outcome with consumer surplus of 12 and producer surplus of 2 , for total welfare of 14. Further suppose that producer surplus goes primarily to the very wealthy, 
so that the latter outcome seems superior on distributive grounds. ${ }^{12}$

Suppose we start with the second rule, aimed at consumer welfare. Let us consider substituting the first rule, aimed at total welfare, combined with an increase in explicit redistribution. To be concrete, suppose that we tax an additional 5 from the rich (perhaps through a higher profits or corporate tax) and distribute an additional 5 to consumers (through a VAT reduction). The net effect on consumers is that they have only 10 rather than 12 in consumer surplus due to the change in the competition law rule, for a loss of 2 , but they also gain by 5 from the tax reduction. In sum, consumers have a net gain of 3. Producers (really, their owners and ultimate beneficiaries) have producer surplus of 10 rather than 2, for a gain of 8, but pay more in taxes of 5. In sum, producers also have a net gain of 3 . Therefore, both groups are better off as a consequence of moving to a competition law regime aimed at maximizing total welfare rather than consumer welfare, accompanied by a redistributive adjustment to the tax and transfer system.

This result - that foregoing indirect redistribution can make all income groups better off - is fairly general, as established in the aforementioned literature. (There are, unsurprisingly, qualifications, but not ones that ordinarily seem very significant in the present context. ${ }^{13}$ ) To redistribute through competition law by employing a consumer welfare standard rather than one directed at total welfare necessarily entails that total welfare will sometimes be reduced. That welfare loss is incurred to enhance redistribution, but even more redistribution could be accomplished directly, without this welfare loss. There is, to be sure, the efficiency cost of redistribution in distorting labor supply, but that happens either way. Redistribution through competition law is an inferior strategy, one that a sensible government would not choose to pursue. ${ }^{14}$

\subsection{Politics}

\footnotetext{
${ }^{12}$ The caveat is included on account of the argument noted at the close of subsection 2.2 that, even if consumers are on average less well off than those who benefit from gains to producers, some of the latter gain goes to individuals who are not extremely wealthy, and much consumer surplus goes to above-median-income individuals, so producer surplus should receive some weight even if one cares strongly about redistribution.

${ }^{13}$ For a substantial treatment of qualifications, see Kaplow (2008), supra note 10, ch. 6C. Many qualifications concern cases in which different tax rates might be applied to different commodities (or analogues thereto), which is inapposite when the means of redistribution involves placing greater weight on consumption as a whole. (One might instead suppose, if the targeting problems involving case-by-case tracing that are mentioned in subsection 2.2 could be overcome, that one might do such adjustments in particular competition law decisions, such as those involving mergers. However, even in that case, it would tend to be true that use of differential commodity taxes would be superior. Moreover, it should be noted that, a priori, the direction of the adjustment could go in either direction; hence, the prescription would be to overweight consumer surplus relative to producer surplus in some cases but to underweight it in others.) One other complication is that prior literature and much of the discussion in the text focuses on labor supply distortion, whereas reductions in producer surplus and profits taxes may affect savings and other decisions as well. However, by substituting profits taxes (rather than income taxes) for reductions in producer surplus, any distortion of such other margins may be held constant as well.

${ }^{14}$ As mentioned in the introduction, this essay does not consider other sorts of justifications for a consumer welfare standard. This section addresses only the point that, in principle, concerns for distribution favor a consumer welfare standard, or at least the underweighting of producer surplus, rather than the maximization of total welfare.
} 
A further consideration, which will be examined here briefly and incompletely, concerns the problem that systems of government do not always operate in sensible ways. Might political considerations somehow make out a case for indirect redistribution through competition law? This subsection suggests a number of reasons to be skeptical.

The basic argument to be addressed is whether one might suppose that the political system engages in too little redistribution from some perspective, thereby providing a justification for competition law to engage in indirect redistribution despite the fact that this approach is less effective than if the redistribution were accomplished directly. To begin with, it is natural to ask how we might know that net redistribution by the government as a whole is too little. One might suppose that more redistribution is always better (perhaps up until the point of full equality). But this perspective ignores efficiency costs of redistribution, which most today concede to be significant. The key point here, emphasized in subsection 2.3 , is that these costs are still borne when redistributing indirectly. Indeed, the aggregate efficiency costs - those due to distortions induced by redistribution itself and the additional distortions in the realm of competition law - are greater with indirect redistribution. Hence, to the extent that costs limit the desired extent of redistribution, this limitation is greater the more one relies on indirect redistribution.

Granting that the appropriate degree of redistribution is limited, might there be reason to believe that the rest of government - in particular, those with control over the tax and transfer system - engages in too little redistribution? It is of course possible to believe that those with such power, often legislatures - err as a matter of ethics or politics - in their redistributive judgments. Such errors could be in either direction, but one possibility is that they redistribute too little. ${ }^{15}$ In making an argument that this is so, as a prerequisite to justifying indirect redistribution through competition law (or otherwise), one would need to justify such a conclusion.

Note further that, if such error was present, systematically and over time, a conundrum is posed: Why might we imagine that a legislature or other political body would both favor too little redistribution and simultaneously empower a subservient government agency to engage in more redistribution, upsetting this judgment (and doing so at higher cost)? A related question is that, if the government as a whole favors what competition authorities take to be too little redistribution, how will the government react if and when it learns that the authority, whose members it appoints, is upsetting its judgment and pursuing additional redistribution? One possibility would be to revoke such authority, if such were feasible. (This might be difficult to the extent that the competition authority can hide its redistributive leanings through rules that on their face do not counsel redistribution but that are frequently applied in ways that do.) Another might be to place more emphasis in appointments decisions on fidelity to the government's

\footnotetext{
${ }^{15}$ Throughout this essay, the argument considered is whether there is too little redistribution that inefficient competition law (underweighting producer surplus) might rectify, albeit inefficiently. One could just as easily ask whether the political system might engage in too much redistribution, which competition law ought to offset, say, by overweighting producer surplus (equivalently, underweighting consumer surplus). There is no a priori basis for focusing on one case rather than the other, but since the literature is overwhelmingly focused on the first possibility, that is the formulation emphasized here. The logic of the analysis is precisely the same from either perspective.
} 
distributive norms rather than on competition policy expertise, which would be costly.

More broadly, one might suspect that the government, when setting and adjusting taxes and transfers over time, in response to changing conditions, would take the competition authority's distributive activities - and those of other government agencies, and effects from market forces, changes in international trade and technology, and so forth - into account. ${ }^{16}$ That is, when taxes and transfers are periodically revised, presumably the degree of redistribution enacted at any point in time reflects judgments and balances of political forces that are applied to the overall economic situation that pertains. If, due to whatever reasons, the poor are seen to be worse, or better, off than was true previously, one might expect there to be more, or less, generous provision accordingly. If one had to guess, one might imagine that there would be an average tendency in the long run for the redistributive system to re-equilibrate fully. ${ }^{17}$

This outcome, however, would be an unhappy one from the viewpoint that greater redistribution would be advantageous. There would not be greater redistribution in the end. Moreover, because some of the redistribution that occurs will have been accomplished indirectly, through competition law, at heightened efficiency cost, the total resources in society will be lower. If fewer resources are distributed in approximately the same way, the net consequence is that all income groups will tend to be worse off (including, in particular, the lower-income individuals one sought to assist). In sum, it is hardly obvious that political considerations resurrect a strong case for indirect redistribution through competition law that, as section 2.3 explains, is in principle an inferior means of redistribution on account of its greater inefficiency.

\subsection{Targeting Revisited}

It is sometimes objected that it would be impractical for the tax and transfer system to adjust so as to offset the distributive effects of particular competition law outcomes. ${ }^{18}$ Likewise, it is hard to see how the government could offset the distributive consequences of particular new parks, roads, schools, regulations, and so forth.

Such case-by-case redistributive offsets, however, are not desirable in themselves and

\footnotetext{
${ }^{16}$ It is, of course, possible that the government will misperceive the existing distribution (or the contribution made by competition authorities, other agencies, or other forces), but it is hardly obvious that such misperception would be in one direction rather than another. Indeed, if competition commentators and authorities regularly champion a consumer welfare target rather than total welfare, yet the difference is often immaterial as some suggest, see Antitrust Modernization Commission, supra note 2, at 3 n. 22 (quoting sources), then it seems possible that the extent of redistribution perceived would exceed that accomplished, in which cases governments might overreact, producing the opposite net distributive consequences.

${ }^{17} \mathrm{By}$ re-equilibrate, it is meant that the system tends to bring the overall degree of distribution achieved in line with that politically desired. The latter, the political objective, is itself changing over time, as values and perceptions change, governments change, and so forth. Even with a moving target, one might suppose that deviations from the target would tend to be reduced, with any net error at a given point being essentially random rather than systematic.

${ }^{18}$ See, e.g., Salop, supra note 11, at 17. Surprisingly, one of Salop's particular objections is that it would be difficult to determine the extent to which producer gains might be passed on to consumers, something that must be determined to apply his preferred consumer welfare standard (but may be less consequential, although still relevant, under a total welfare standard).
} 
largely beside the point to the present argument. Taxes and transfers are and should be based on the totality of individuals' circumstances. For individuals at a given, say, low level of income, their need for income supplementation reflects their income level and what such income can purchase. Whether their income level and the relevant price levels of consumption goods are a little higher or lower than they otherwise might be because of some particular technological innovation, a change in consumer tastes, different trade flows, a new pollution regulation, widening a highway, or this or that merger decision is immaterial.

To reflect on this point, suppose that the price of cocoa increased because weather damaged a significant part of the crop. Individuals who particularly like chocolate would be worse off. Should government taxes and transfers adjust in light of this particular event? Performing all manner of studies to trace its distributive incidence? And if, say, the next year, the price is unusually low, should countervailing distributive adjustments be made? Obviously not. Redistribution should depend on individuals' overall circumstances, and that is what tax and transfer systems are designed to reflect. ${ }^{19}$

Observe that the foregoing point is closely related to the analysis in subsection 2.2 of the targeting efficacy of competition law. Distributively oriented competition law, we might imagine, would trace the subtle effects of each particular decision, such as that concerning a merger, to determine what weighting of consumer and producer surplus would be optimal in light of distributive consequences. This case-by-case approach is to a significant extent infeasible and in any event often quite expensive, but this limitation was explained not to constitute a good reason for ruling out placing extra weight on consumer welfare if one is concerned about redistribution. The reason is that, on average, consumers tend to be less wealthy than producers. Thus, placing extra weight on consumers tends on average, over a large number of cases, to somewhat increase redistribution by moving some income from richer individuals to those who are less well off. Of course, it is precisely on this aggregate basis that the tax and transfer system operates as well.

\section{Price Elevation}

\subsection{Overview}

For all the debate about objectives of competition law and, in particular, whether a welfare-based measure should reflect only consumer welfare or encompass total welfare, only modest attention has been given to why the difference matters. Traditionally, the subject has been seen as relevant primarily (only?) to the assessment of mergers, in particular, whether the extent to which efficiencies will likely be passed through to consumers is of consequence. A pure, simple consumer welfare view would require efficiencies to be passed through sufficiently to offset any adverse price effects on account of the merger's competitive consequences.

\footnotetext{
${ }^{19}$ Some causes, particularly those under individuals' own control, should be taken into account because of the concern for incentives. Such considerations are not centrally implicated in considering, say, individual consumer's behavior in response, say, to changes in various price levels as a consequence of some merger of firms producing an intermediate good.
} 
In the context of exclusionary practices, there has been much debate over the proper test. ${ }^{20}$ Much of this analysis is only loosely connected to the welfare standard (although some proposed tests are themselves welfare tests, not further concretized). A particularly interesting example is that many favor tests for predatory pricing and other potentially abusive practices that ask whether equally or more efficient producers would be eliminated from the market, an orientation that seems more appropriate if the objective of competition law is not consumer welfare, or even total welfare, but rather producer welfare. ${ }^{21}$

For price fixing, the standard is not generally regarded to matter (it usually is not addressed), for the prohibition is not seen as controversial. Specifically, elevating price reduces both consumer welfare and total welfare (the latter due to deadweight loss, as already explained), so the choice between these standards seems immaterial.

This section offers a new, complementary perspective. In particular, it inquires into how the degree of price elevation affects the analysis of competition policy. For mergers, the relevant consideration for present purposes is the degree of elevation pre-merger (taking the increment expected to be produced by the merger as given). For exclusionary practices that, say, maintain existing monopoly power, the extent of current price elevation would matter. For price fixing, the question would be the extent of price elevation produced by the coordinated behavior in question (or facilitated by the practice under challenge).

The core analytical point, developed in the next subsection, is that the marginal loss in consumer welfare from price elevation - beginning at the competitive level at which price equals marginal cost - is initially high but falling with further elevations. By contrast, the marginal loss in total welfare (rise in deadweight loss) from price elevation is initially negligible but rising with further elevation. The final subsection identifies some of the implications of these phenomena.

\subsection{Analytics}

Begin with consumer welfare, equivalently, consumer surplus. Specifically, consider some given price elevation, in one case starting from the competitive price, equal to marginal

\footnotetext{
${ }^{20}$ See, e.g., Kaplow and Shapiro, supra note 1, at 1191-94 (briefly introducing the subject and citing authors presenting competing views).

${ }^{21}$ See id. at 1193 . Consider the following stylized example in the predatory pricing setting in which the test of how low an incumbent monopolist can price in response to an entrant with constant marginal cost and very small fixed costs is determined by the prospective entrant's marginal cost relative to that of the incumbent's. Pricing just below the entrant's marginal cost when the incumbent is slightly more efficient will exclude a rival whose presence, let us suppose, would have resulted in a lower price, which would definitely raise consumer surplus and probably raise total surplus as well (if the gain in consumer surplus is nontrivial, since the entrant's cost disadvantage is tiny and thus its attracting sales does not much reduce production efficiency and thus producer surplus). One could find the consumer-surplus-maximizing gap - the degree to which the entrant could be less efficient yet consumer surplus would still rise - and also the total-surplus-maximizing gap, which would be smaller although still positive, as just explained. Hence, on this continuum, allowing the incumbent to exclude any less efficient rival entails giving more weight to producer surplus over consumer surplus than would a total welfare test - indeed, in the simplest setting, total weight to producer surplus and none to consumer surplus.
} 
cost (which for simplicity will be taken to be constant) and, in a second case, starting from a significantly elevated price. This comparison is depicted in Figure 1.

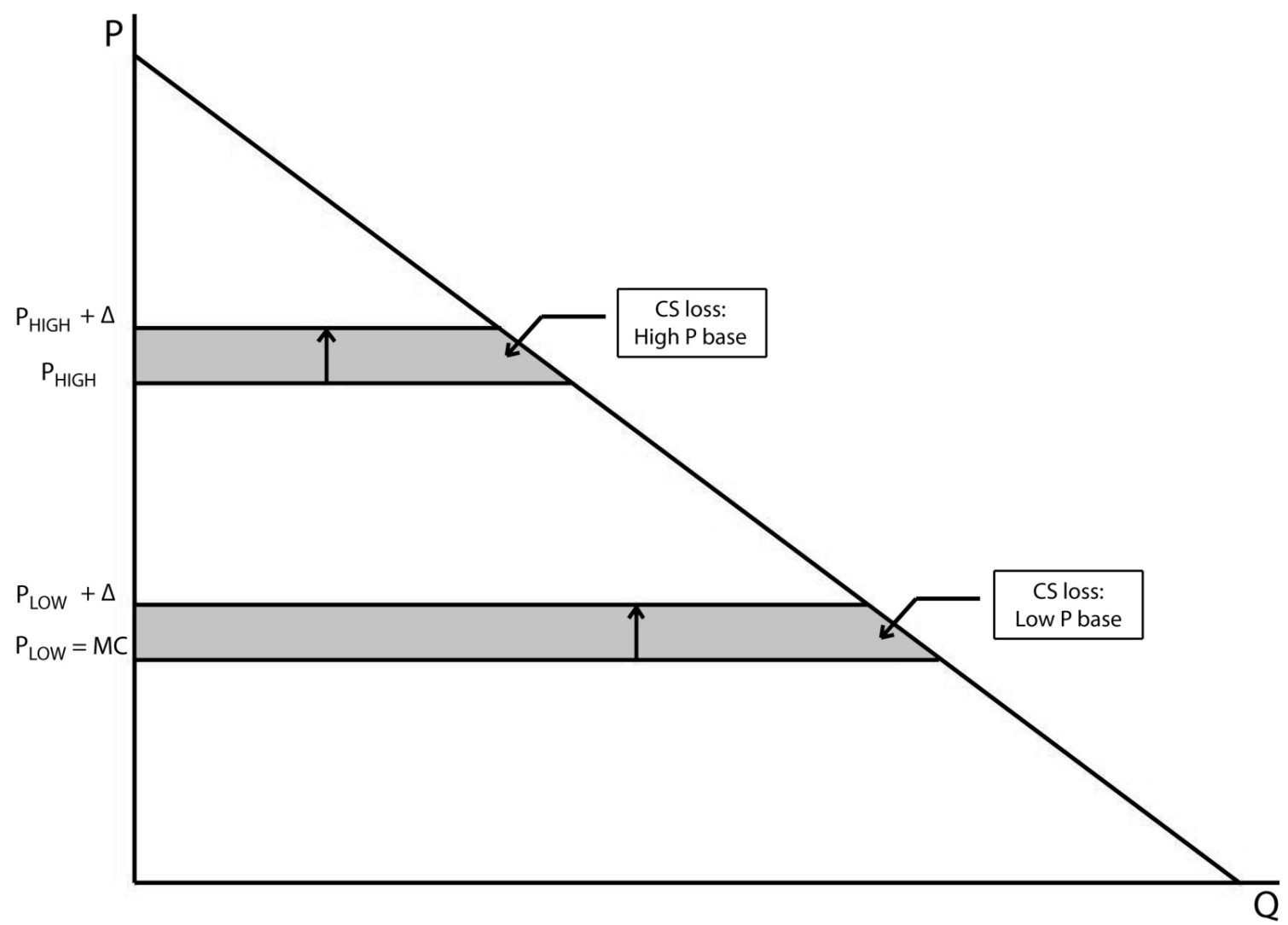

Figure 1: Consumer Surplus Loss due to Price Increase from Different Base Prices

In this Figure, quantity $(\mathrm{Q})$ is on the horizontal axis and price $(\mathrm{P})$ on the vertical axis, as is conventional. The diagonal line with the negative slope is the demand curve (assumed to be linear for simplicity). It is supposed that marginal cost (MC) is given by the lowest horizontal line (it is constant), and this also is the competitive price $\left(\mathrm{P}_{\text {LOW }}\right)$. The Figure depicts two price increases of equal magnitude $(\Delta)$, one starting from the competitive price and the other starting from a much-elevated price $\left(\mathrm{P}_{\mathrm{HIGH}}\right)$.

Consumer surplus (CS), as explained in the introduction, is the difference between what consumers are willing to pay (indicated by the demand curve) and what they actually pay. Hence, the area between the demand curve and the horizontal line at the prevailing price indicates total consumer surplus. The loss in consumer surplus from a price increase is therefore indicated by the degree by which this area shrinks. In the diagram, these are trapezoids, which have an area approximately equal to that of horizontal rectangles. For the rectangular portion, the bulk of the consumer surplus loss, the area is given by the quantity that consumers continue to buy times the magnitude of the price increase, which quantity is transferred to producers as 
profits. The small additional area, the triangles at the right end of the trapezoids, reflects the lost consumer surplus on account of purchases that consumers now eschew on account of the price elevation. (Consumers' valuations for those units are necessarily less than the elevated price, which is why they desist from the purchases.)

It is obvious from the diagram that, the higher the base price, the less is the loss in consumer surplus on account of a given increment to the price. The reason, simply, is that the quantity demanded is lower at a higher base price, so the price increase applies on a smaller base. Although it is already well understood that total consumer surplus falls more as prices rise further, the point emphasized here is that the incremental or marginal loss in consumer welfare is falling as price rises. In the diagram, the reduction in consumer surplus from the higher base price is roughly half that occurring at the lower base price.

Consider now the reduction in total welfare or surplus, which is the rise in deadweight loss (DWL) from the price increase. The comparison for different base prices is depicted in Figure 2.

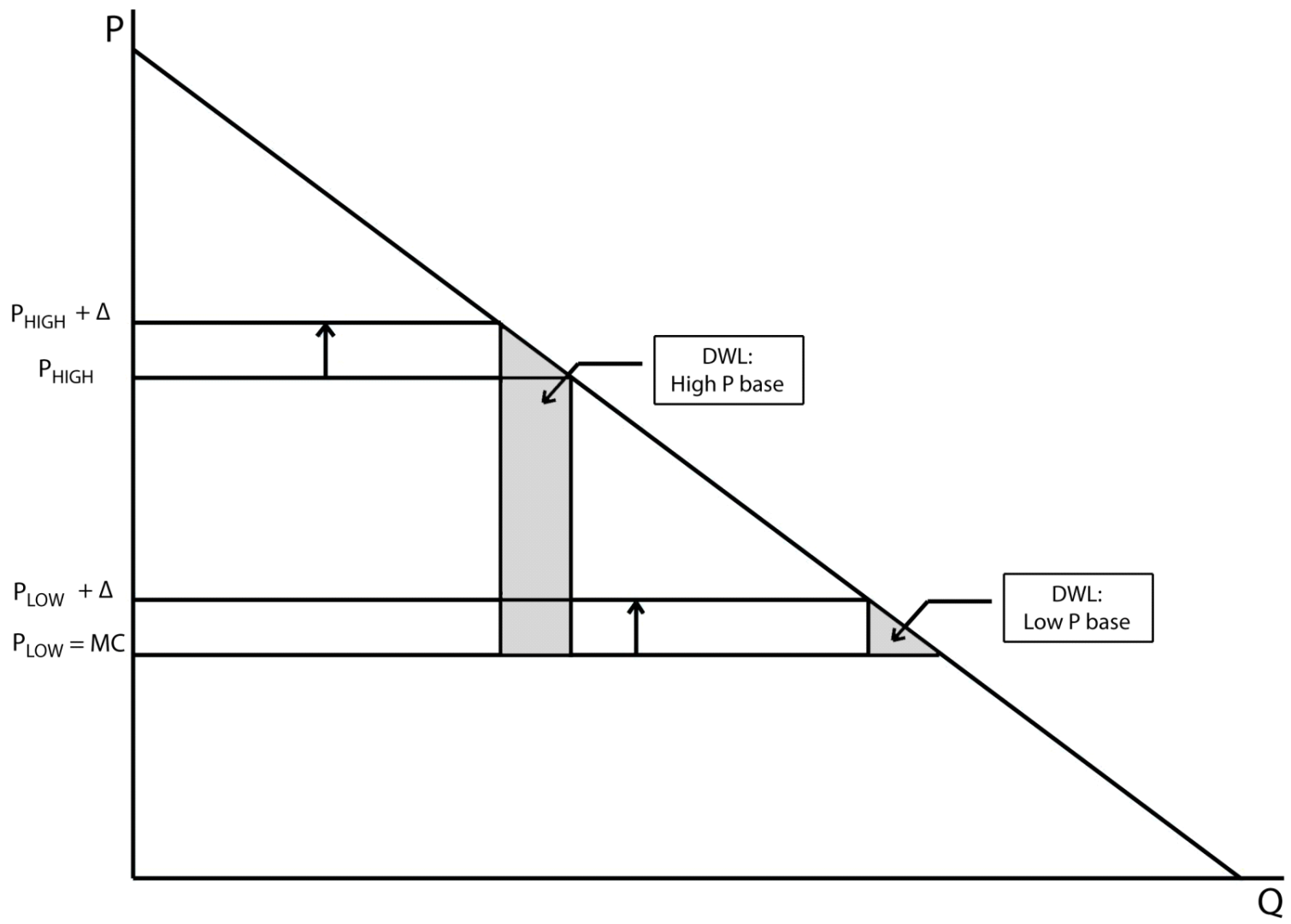

Figure 2: Total Surplus (Deadweight) Loss due to Price Increase from Different Base Prices 
Total deadweight loss is given by the area of the triangle with marginal cost (the competitive price) as the base, the vertical line connecting this line to the demand curve at the prevailing quantity and price, and the corresponding portion of the demand curve. This triangle accords with the definition of deadweight loss as the difference between what consumers would be willing to pay (given by the height of the demand curve) and marginal cost (the lowest horizontal line) for those units no longer purchased on account of the price elevation (those units to the right of the vertical line through the point on the demand curve corresponding to the prevailing quantity and price, across to the point where the demand curve crosses the marginal cost curve).

As the diagram indicates, incremental deadweight loss is quite small when price is elevated only slightly. ${ }^{22}$ However, given a significant initial price elevation, incremental deadweight loss is substantial, as indicated by the vertical trapezoid in the figure. As drawn, the ratio of the incremental deadweight loss from the high base price to that from the low (competitive) base price is roughly ten to one. (This is a crude approximation from the figure; the precise ratio is immaterial.)

Now, let us combine these two results. The ratio (high to low base price) for consumer surplus is roughly $1: 2$, or equivalently $0.5: 1$, and that for total surplus is $10: 1$. Thus, the ratios in this example differ by a factor of 20. That is, in this example the impact on consumer surplus relative to total surplus is twenty times as high when starting from a competitive price than a significantly elevated price. Equivalently, the impact on total surplus relative to consumer surplus is twenty times greater at the significantly elevated price than at the competitive price. This stark difference is attributable to the two identified factors: the marginal consumer surplus sacrifice starts high and falls gradually with price elevation; the marginal total surplus sacrifice starts at a negligible level and rises (total deadweight loss accelerates) with price elevation. Accordingly, to the extent that the magnitude of welfare consequences matters for competition law, whether one cares about consumer welfare or total welfare can make a great deal of difference depending on whether and how elevated is the base price at the outset.

\subsection{Implications}

Consider first the implications for enforcement relating to price fixing. ${ }^{23}$ For consumer or total welfare objectives, large elevations are worse. For consumer welfare, twice the elevation is less than twice as bad (because the marginal decline in consumer surplus is falling, as just explained) whereas for total surplus, twice the elevation is more than twice as bad (in the simple case depicted in subsection 3.2 , it is four times as bad). ${ }^{24}$

Suppose that consumer welfare is the objective. In that case, competition authorities should be reluctant to allow modest price increases to slip by since they are still fairly harmful

\footnotetext{
${ }^{22}$ At the margin, deadweight loss is in fact zero for an infinitesimal increase in price above marginal cost.

${ }^{23}$ The discussion of price fixing summarizes some of the points developed in depth in Kaplow, Toward a Test for Price Fixing, Antitrust Law Journal (forthcoming 2011).

${ }^{24}$ This figure arises because deadweight loss is the area of a triangle, and with twice the elevation, the base and height of the deadweight loss triangle are each twice as high, so the area is four times as great.
} 
from the consumer welfare perspective. However, modest price elevations are more difficult to detect, and there is a greater risk of false positives when attempting to target such increases. ${ }^{25}$ Similarly, if modest elevation is taken to be a serious problem, enforcers should be aggressive against ambiguous practices that might facilitate coordinated price elevation, which has attendant false positive risks.

Now suppose instead that the goal is to maximize total welfare. Since deadweight loss is very small for modest price elevations, it would not be important to target such cases, and they might best be avoided due to false positive risks (except when price fixing is obvious). Instead, enforcement would concentrate on large elevations. Such cases pose much less risk of false positives and attendant chilling costs.

Next, consider horizontal mergers. Conventional wisdom - and merger guidelines in most jurisdictions ${ }^{26}$ - impose stricter scrutiny on mergers for which the pre-merger degree of concentration and thus expected price elevation is greater. The notion is that, the worse is the initial situation, the less we should tolerate further deterioration.

This approach is rational if a total welfare standard is embraced. The higher the initial price elevation, the greater is the loss in total surplus (increase in deadweight loss) from a given further increment to price, as just explained. Indeed, marginal deadweight loss is negligible when the baseline price is competitive or nearly so, in which case it makes little sense to devote great resources and potentially sacrifice production efficiencies for mergers in such industries taking as given the degree of price elevation entailed.

By contrast, if consumer welfare were the objective, priorities should be reversed. For a given price elevation, scrutiny should be the toughest where the initial price elevation is low and progressively weaker as the initial price elevation is larger. This approach seems, however, to be the opposite of current policy. And this is so despite the common endorsement of consumer welfare standards in the very merger guidelines that embrace this approach. ${ }^{27}$

One possible response is that, for a given increment to concentration (say, the increase in

\footnotetext{
${ }^{25}$ An interesting but unappreciated point is that, from a pure consumer welfare perspective, some degree of false positives could be desirable. Consider, for example, a competitive industry with rising marginal costs. Suppose that the prospect of false positives depresses prices a bit below the competitive level (because this is anticipated to reduce the prospect of mistaken liability and resulting fines). Such price depression is inefficient (total welfare falls), but consumer surplus rises. Specifically, on units that are still sold, consumers pay less. Some consumers who desire to purchase cannot (rationing is entailed in such an equilibrium), but for modest price depression, the surplus lost on this account is less than the surplus gain to those who continue to buy.

${ }^{26}$ See, e.g., U.S. Department of Justice \& Federal Trade Commission, Horizontal Merger Guidelines $\S 5.3$ (2010) [hereinafter U.S. Merger Guidelines]; European Union, Guidelines on the Assessment of Horizontal Mergers, European Commission Regulation 139/2004, \$ף 19, 20 (2004) [hereinafter EU Merger Guidelines].

${ }^{27}$ See, e.g., U.S. Merger Guidelines, supra note 26, $\$ 10$ ("the Agency considers whether cognizable efficiencies likely would be sufficient to reverse the merger's potential to harm consumers in the relevant market, e.g., by preventing price increases in that market"); EU Merger Guidelines, supra note 26, $\$ 79$ ("The relevant benchmark in assessing efficiency claims is that consumers will not be worse off as a result of the merger."). However, as explained in note 2 , such endorsements of a consumer welfare standard are arguably ambiguous and also may be presented for the sake of appearances when actual policy and practice is to the contrary.
} 
$\mathrm{HHI}$ ), the price increment will be greater when the pre-merger concentration is worse. Here, two points are in order. First, this phenomenon would need to be true to a sufficient degree to outweigh the considerations adduced here. (For example, in the illustration in subsection 3.2, there was a twenty to one difference between the two criteria; even for more modest differences that may be more realistic in practical merger review, the gap may well be substantial). Second, it is hardly obvious that such is the case. For example, if one supposes Cournot competition, in a simple symmetric setting the industry-wide average output-weighted price-cost margin is equal to the HHI divided by the industry elasticity of demand. ${ }^{28}$ In that (special and simplified) case, a given increment to the HHI has the same impact on price regardless of the pre-merger HHI (for a constant-elasticity demand function). On the other hand, if the concern is not with unilateral market power but rather with coordinated effects - facilitating collusion - it may well be that the incremental risk is greater the higher the pre-merger HHI. ${ }^{29}$

Another question central to merger enforcement is whether one should require a demonstration of a nontrivial (expected) anticompetitive effect as a prerequisite to condemnation. If one is only concerned with consumer welfare and, moreover, if marginal consumer welfare costs are greatest in industries that initially have nearly competitive prices, it might seem that this degree of leniency is inappropriate. A common justification is that mergers should perhaps be presumed to generate some efficiencies. Yet if there is a pure consumer welfare standard, this ground is problematic. One might further believe that most efficiencies tend to be passed on, so mergers with little anticompetitive potential are likely to decrease price, or at least not increase it. However, the view that pass-through is typical is difficult to reconcile with approaches toward efficiency defenses that presume no pass through and impose difficultto-meet burdens on merging parties to demonstrate the contrary.

This preliminary, suggestive analysis of the implications of the different welfare tests should be extended to all areas of competition law. With exclusionary (abusive) practices, we should be more concerned about practices that might prevent a given reduction in the dominant firm's price when that price is very high if our objective is total welfare, but relatively more concerned when that price is lower under a consumer welfare standard. Again, this latter priority suggestion seems contrary to conventional wisdom and practice. There are countervailing considerations, such as the fact that false positive risks are less when prices are more elevated. Yet some of the false positive risk, again, involves the loss of production efficiency, which is fully credited under a total welfare objective but only to the extent passed on to consumers under a consumer welfare standard.

\section{Conclusion}

The matter of competition law's proper objectives is complex and controversial. Many

\footnotetext{
${ }^{28}$ See, e.g., Kaplow and Shapiro, supra note 1, at 1085.

${ }^{29}$ Yet another view, which logically follows for those who believe that effective coordination (even without highly explicit communication) is inevitable when there is fairly high concentration in industries with otherwise conducive conditions, would be that the incremental risk of collusion is actually falling once HHI's are fairly high, which again arguably favors a prioritization opposite to those in existing merger guidelines.
} 
of its dimensions - objectives other than welfare and other aspects of the debate among welfare standards - are not considered here. Instead, attention is focused on two points relating to the choice between a consumer and total welfare standard that seem largely unappreciated.

First, distributive objectives are often seen as justifying a consumer welfare standard, or at least underweighting producer surplus relative to consumer surplus. This essay argues that targeting objections to this view are not decisive since, in fact, there is some redistributive effect, at least on the surface, because those who benefit from producer surplus are on average wealthier than consumers as a whole (even though the latter group, reflecting the distribution of consumption in a society, is also significantly weighted toward those more well off). Nevertheless, it is more efficient to confine competition law to the maximization of total welfare and achieve redistribution solely through the tax and transfer system. The same redistribution can be achieved at less cost, or more redistribution at the same cost; in general, all income groups can be made better off.

Second, under the two different welfare standards, the relevance of the degree of baseline price elevation is quite different. For a given increment to price - whether attributable to a horizontal merger, a dominant firm's exclusionary practice, or price fixing - the consumer welfare sacrifice is highest when the baseline price is competitive and lower the greater is the baseline price elevation. By contrast, for total welfare, the sacrifice is negligible when the baseline price is competitive and rises with the degree of price elevation. The relative differences between the two standards in the two settings can be very large. Implications for policies toward price fixing (and facilitating practices), horizontal mergers, and dominant firm's purportedly abusive practices were sketched. In some cases, they suggest that rules that are thought to be grounded in consumer welfare maximization are contrary to what is implied and instead are more in accord with total welfare maximization.

This essay considers only two of competition law's possible goals - consumer welfare and total welfare - and considers only two aspects thereof. Nevertheless, since many believe that competition law should be substantially concerned with welfare, and since the two main conclusions here run counter to much conventional wisdom regarding these objectives and their perceived implications, the present analysis is potentially important for competition policy. 